TEZCATLIPOCA (POST)MODERNO: REINTERPRETACIONES DE

LA FIGURA DEL ESPEJO HUMEANTE EN LA NARRATIVA

MEXICANA CONTEMPORÁNEA

\title{
(Post)modern Tezcatlipoca - Reinterpretation of the Figure of the Smoking Mirror in Contemporary Mexican fiction
}

\author{
EDYTA ANDZEL-O'SHANAHAN \\ eandzel@yahoo.co.uk
}

\begin{abstract}
Resumen: el propósito del presente trabajo es el de rastrear la presencia de la figura de Tezcatlipoca y de los mitos relacionados con él en la literatura mexicana de los siglos XX y XXI. Uno de los dioses principales en la cosmovisión azteca, el omnipotente y omnipresente dios de la guerra, capaz de entender los secretos de los corazones humanos y de revelar el destino, reaparece en la narrativa contemporánea con todo su rico simbolismo. Las reelaboraciones de su imagen se inscriben, sin embargo, dentro de una neocultura, fuera de su contexto original. Los ejemplos selectos ilustran la reinterpretación del pensamiento mítico indígena y la adaptación del valor simbólico del mito a la realidad mexicana transculturada.
\end{abstract}

Palabras clave: mito indígena, Quetzalcóatl, Tezcatlipoca, transculturación

\begin{abstract}
The aim of this article is to analyse the manifestations of the figure of Tezcatlipoca and related myths in the $20^{\text {th }}$ and $21^{\text {st }}$ century Mexican literature. One of the principal deities in the Aztec mythology, the omnipresent and omnipotent god of war, able to understand the secrets of human beings and reveal their destiny, Tezcatlipoca reappears in contemporary fiction with all of his rich symbolism. The reformulation of his image, however, is embedded into a new culture, outside its original context. Selected examples illustrate the reinterpretation of the indigenous mythical thinking and the adaptation of the symbolic value of myth to the transculturated reality of Mexico.
\end{abstract}

Keywords: Indigenous Myth, Tezcatlipoca, Quetzalcoatl, Transculturation 
Bernal Díaz del Castillo, el famoso testigo ocular de la conquista de México, relata sus impresiones de la imagen de Tezcatlipoca de la manera siguiente:

Luego vimos a otra parte, de la mano izquierda, estar el otro gran bulto del altar de Vichilobos, y tenía un rostro como de oso, e unos ojos que le relumbraban, hechos de sus espejos, que se dice tezcat, y el cuerpo con ricas piedras pegadas según y de la manera del otro su Vichilobos, porque, según decían, entrambos eran hermanos, y este Tezcatepuca era el dios de los infiernos, y tenía cargo de las ánimas de los mejicanos, y tenía ceñido al cuerpo unas figuras como diablillos chicos, y las colas dellos como sierpes, y tenía en las paredes tantas costras de sangre y el suelo bañado dello, como en los mataderos de Castilla no había tanto hedor. E allí le tenían presentado cinco corazones del aquel día sacrificados. (Díaz del Castillo, 1998: 202)

El culto a Tezcatlipoca, junto con otras deidades mexicanas, despertó en los españoles un fuerte sentido de terror, la repugnancia, el rechazo inmediato; fue tachado de diabólico y bárbaro. Los europeos tardarán siglos en comprender el significado de los sacrificios humanos en la cosmogonía nahua y el papel del ser humano en perpetuar el ciclo de los cuerpos celestes, de la vida y muerte. La recuperación del mito prehispánico, con su riqueza semántica simbólica, no ocurrirá plenamente hasta el siglo XX y coincidirá con el redescubrimiento del mito como acervo cultural con significados universales sobre todo por las corrientes de la vanguardia europea.

A partir de la Primera Guerra Mundial surge en Europa "una fuerte tendencia antirracionalista que encuentra su principal forma de expresión en el mito y en el símbolo" (Ordiz, 2003: 1). De este modo, la literatura europea recupera el mito como un modo de manifestación estética opuesta al "cientifismo racionalista" (ob.cit.). Así mismo, América Latina también redescubre el mito prehispánico, visto ya no como una superstición ni un idealizado motivo indianista, sino como una de las claves para el entendimiento de su identidad. No obstante, no se trata de un simple recuento de los mitos, ya que con la conquista empezó el proceso de la transculturación, caracterizado no sólo por la recuperación de lo subalterno, sino también por las pérdidas, modificaciones y reinterpretaciones de los modelos culturales procedentes de las culturas que entran en contacto. De esta manera surge una cultura nueva, original, heterogénea, que constituye mucho más que una simple mezcla de varios elementos multiculturales, puesto que la transculturación es un proceso dinámico y modificador, en el que los componentes culturales se ven alejados de su contexto original y experimentan una reconfiguración y resemantización.

El propósito del presente trabajo se centra en las representaciones de Tezcatlipoca o los mitos relacionados con esta deidad y sus funciones en la literatura mexicana moderna, siempre advirtiendo al lector que los ejemplos analizados más adelante no son sino una muestra del rico corpus literario que incluye el mito prehispánico y que el análisis mitopoético de estas obras no constituye la única pauta interpretativa válida. No obstante, los ejemplos escogidos para este trabajo permitirán observar la variedad de las reelabroaciones estéticas y conceptuales del mito indígena desde la misma 
perspectiva letrada y mestiza. A través de varias generaciones de escritores, en diferentes contextos socio-históricos y en diversos subgéneros narrativos, desde la nueva novela histórica hasta la novela de terror, el mito está presente en la creación literaria mexicana. La inclusión del mito prehispánico en las novelas analizadas adelante pone en relieve la importancia del legado indígena, entendido no como una parte del pasado lejano sino como un hilo indispensable en el tejido de la nueva cultura híbrida contemporánea. El constante diálogo que la narrativa mexicana moderna, basada en las pautas europeas, mantiene con las temporalidades míticas prehispánicas propicia la creación de una nueva sensibilidad estética propiamente latinoamericana (Morales, 1996: 410).

Tezcatlipoca era una de las deidades más misteriosas del panteón azteca y gracias a su rico simbolismo, una de las figuras mitológicas predilectas de la literatura mexicana de los siglos XX y XXI. Según Bernardino de Sahagún, Tezcatlipoca "era tenido por verdadero dios e invisible, el cual andaba en todo lugar en el cielo, en la tierra, y en el infierno" y "cuando andaba en la tierra movía guerras, enemistades y discordias" (2010: 2). Además, el dios caprichoso "solo daba las prosperidades y riquezas, y [...] él solo las quitaba cuando se le antojaba" (ob.cit: 3). Su complejidad queda ilustrada por sus numerosos nombres: Tezcatlipoca, por ejemplo, significa "El espejo que humea" y se refiere al atributo más importante de este dios, un espejo de obsidiana capaz de revelar el destino humano fijado por los signos del calendario ritual tonalpouhalli; el nombre Youhalli Ehecatl, "El viento nocturno", está estrechamente relacionado con la idea de destrucción y el origen de numerosas enfermedades; como Yaotl ("El enemigo") Tezcatlipoca era el venerado diosguerrero; su nombre Telpochtli aludía a su virilidad y eterna juventud; como teiximatini era conocedor de los seres humanos y los secretos de sus corazones (Olivier, 2003: 14-44). Tezcatlipoca poseía el don de la ubicuidad y de la metamorfosis: asumiendo varias formas, a menudo aterradoras, espantaba a los seres humanos y se burlaba de ellos, como si fueran juguetes en sus manos (ob.cit: 17). El mago supremo, el príncipe de la oscuridad nocturna, un dios voluble y malévolo, tenía su doble en el jaguar, el animal relacionado con el agua, la noche y la tierra. Tezcatlipoca tienía también un lado positivo y poderes creativos. Según uno de los mitos, Tezcatlipoca y su hermano Quetzalcóatl participaron en la creación de la tierra, rompiendo en pedazos el cuerpo del monstruo Tlaltecuhtli que flotaba en las aguas primordiales. Una parte del monstruo se convirtió en cielo, la otra mitad en tierra firme. De los restos de Tlaltecuhtli los hermanos divinos crearon árboles, plantas, ríos, pozos, valles y montańas (Heyden, 1989: 88). Según el mito de los cinco soles, Tezcatlipoca presidía sobre el primer sol (o edad) de la tierra, habitado por los gigantes. Aquel sol terminó a consecuencia de la batalla entre Tezcatlipoca y Quetzalcóatl, cuando el Espejo Humeante se convirtió en el jaguar. Sin embargo, la victoria de la Serpiente Emplumada no duró mucho: el sol 4Ehécatl fue destruido por los huracanes causados por Tezcatlipoca (Heyden, 1989: 87; Miller, Taube, 1993: 164).

El motivo de la enemistad entre los dos hermanos divinos es uno de los más importantes mitemas en la mitología nahua. Lo encontramos de nuevo en 
el mito de la caída de Tollan, en el que Quetzalcóatl se identifica con Ce-Acatl Topiltzin, el gobernante de los Toltecas. Tezcatlipoca es el causante de la borrachera del gran bienechor tolteca, quien tuvo después una relación incestuosa con su hermana y avergonzado huyó de su pueblo. El regalo astuto de Tezcatlipoca era un espejo que reflejaba la imperfecta naturaleza de Quetzalcóatl, quien "siendo un dios, creía que no tenía rostro. Era eterno. Ahora, al descubrir sus facciones humanas en el reflejo del cristal, temió tener, también, un destino humano" (Fuentes, 2000: 11). Aunque, tanto en la mitología como en la literatura mexicanas, el enfrentamiento entre los dos hermanos divinos simboliza la dicotomía entre la vida y la muerte, el bien y el mal, entre la paz y la guerra, entre la sabiduría civilizadora y la magia, esta oposición difiere esencialmente de la cosmovisión en la tradición judeocristiana. En la mitología nahua, ni la derrota ni el triunfo de ninguno de los dos dioses pueden ser completas y definitivas. Ambos son indispensables para el mantenimiento del equilibrio al nivel cósmico, se complementan mutuamente.

El mito, incluido el prehispánico, está presente en la obra de Carlos Fuentes a lo largo de su trayectoria literaria. Tezcatlipoca aparece junto con otras deidades mexicas en el relato Por boca de los dioses, en el que representan de una manera simbólica el pasado no asimilado. Sin embargo, es en Terra Nostra donde el motivo de la rivalidad entre Tezcatlipoca y Quetzalcóatl se convierte en el punto focal de las indagaciones sobre la identidad mexicana. En la conquista de México y en la fusión de varias culturas Fuentes ve la clave para el entendimiento de la identidad heterogénea de la nación. "De la catástrofe de la Conquista nacimos nosotros, los mexicanos. Fuimos, inmediatamente, mestizos. [...] Somos el rostro de un occidente rayado, como dijo el poeta mexicano Ramón López Velarde, de moro y de azteca- y, añadiría yo, de judío y de africano, de romano y de griego", asegura Fuentes (2000: 16). "Nunca más podremos ocultar nuestros rostros indígenas, mestizos, europeos: son todos nuestros" (ob.cit.: 21). Esta filosofía del nacimiento de la identidad híbrida mexicana consigue su máxima expresión en Terra Nostra.

La novela del escritor mexicano rompe con el esquema racionalista de comprender la historia como un suceso de causas y efectos en el tiempo linear. Como pregunta Polo Febo en la novela, "¿Principio o fin, causa o efecto, problema o solución: qué estamos viviendo?" (Fuentes, 2012: 26). Carlos Fuentes ofrece al lector una visión alternativa de la historia que "viola los códigos de la certeza realista", en la que "la historia se reinventa, se falsifica el dato, se crea el dato que no existe, se contradice la información oficial" (Vidaurre Arenas, 2004a: 8,10). Los personajes históricos se ficcionalizan, identidades se funden en personajes arquetípicos, aparecen personajes literarios e incluso más, los hechos históricos se combinan con "la memoria de cuanto pudo ser y no fue" (Fuentes, 2012: 689), igual que en el teatro de la memoria del maestro Valerio Camillo. Como ocurre a menudo en la nueva novela histórica, a esta visión alternativa de la historia se suma también el mito (Jastrzębska, 2013: 27, 89-90).

En Terra Nostra el encuentro entre dos mundos, el viejo y el nuevo, está relatado dos veces: una vez por el peregrino, el narrador intradiegético homodiegético de la segunda parte de la novela y otra vez en la "carta de 
relación" de Guzmán. Mientras el primer relato tiene un carácter onírico, se inscribe en la temporalidad mítica y se refiere al descubrimiento del Nuevo Mundo, el segundo puntualiza datos relacionados con la conquista, motivada por "el deseo de oro y riquezas" (Fuentes, 2012: 811), cuando "a su paso, la esforzada hueste española derrumbó ídolos, incendió templos y destruyó papiros de la abominable religión del Diablo. [...] En cada aldea herró a algunos, mató a otros, prometió la vida a muchos más si aceptaban vivir como bestias de carga, dio licencia a sus soldados para tomar las mujeres que apetecieran, y espantó a todos" $(864,865)$. Ambos relatos muestran dos caras del mismo fenómeno, tanto en su afán creador como en su poder destructivo. Para ilustrar esta dual naturaleza de la realidad Fuentes recurre al mito de la lucha entre Tezcatlipoca y Quetzalcóatl. En los siguientes párrafos intentaremos analizar la función metafórica de este mito en la novela, centrándonos en la segunda parte de Terra Nostra.

Notemos primero que a las orillas del Nuevo Mundo llegan dos personajes: el viejo marinero Pedro y el peregrino, hijo de Felipe, El Hermoso, y Celestina. Pedro emprende el viaje buscando una utopía de "la tierra libre, la parcela de la felicidad, el mundo nuevo emancipado de las injusticias, las opresiones y los crímenes del viejo mundo" (575). Sus ilusiones están condenadas al fracaso: Pedro muere sacrificado poco tiempo después de haber llegado a lo que pensaba ser un nuevo Edén. El Nuevo Mundo no era la esperada tierra virginal sino un mundo donde "la belleza de las cosas, la fraternal comunidad de las posesiones, el apego a la vida, convivían con estas ceremonias del crimen", donde coexistían "el culto de la vida y el culto de la muerte" (522). El peregrino, libre de la actitud idealista y las ilusiones de su viejo compańero, sin ideas preconcebidas, es un aventurero joven, desarraigado, sin "nombre y hogar, mujer y descendencia, honor y hacienda" (432). Quizás precisamente su condición del hombre sin pasado y la mente abierta son las cualidades que le permiten al peregrino descubrir la tierra nueva, empeñarse en entenderla rechazando "la tentación de condenar lo que ignoraba" (ibid.: 526), comprender el papel del hombre blanco en esta tierra y formular las preguntas clave de esta parte de la novela: "¿Nos descubren ellos... o les descubrimos nosotros?" (462), "si he llegado, ¿a dónde he llegado?; si soy, ¿quién soy?" (498).

Las primeras pistas le proporciona al peregrino el viejo de la memoria. Tras haberle explicado algunos de los conceptos más importantes de la cosmovisión azteca, la creación del mundo del cuerpo de la diosa de la tierra, el nacimiento de los primeros hombres, el significado de los sacrificios humanos, el calendario ritual de 260 días y la leyenda de los soles, el anciano le revela al peregrino su identidad:

Tú plantaste, tú cosechaste, tú tejiste, tú pintaste, tú labraste, tú enseñaste. Tú dijiste que bastaban el trabajo y el amor para compensar la vida que nos dieron los dioses. [..] Y cada vez que el sol murió, tú huiste llorando hacia el mar. Y cade vez que el sol renació, regresaste a predicar la vida. (483) 
El peregrino entonces, como personaje arquetípico que simboliza al hombre europeo llegado al Nuevo Mundo, es el esperado Quetzalcóatl, dios fundador, portador de la civilización y de la cultura, educador, predicador del bien y de la paz. Parece que el enigma de su identidad queda resuelto. En la tierra nueva, sin embargo, nada es lo que aparenta y cada cosa inevitablemente muestra "la duplicidad de su natura" (529). Poco después, el peregrino encuentra a un monstruo fantasmal con el corazón latente asomándose entre las costillas de su pecho abierto: una forma espantosa del dios Tezcatlipoca, con la cara y el cuerpo del peregrino: su exacto doble, su gemelo, su espejo, su enemigo hermano (512). Tres veces el peregrino se negará a asumir esta horrorosa identidad. La primera vez, devolviéndole el corazón al fantasma del bosque. La segunda vez, rechazando el destino del ixiptla, la personificación y la imagen de Tezcatlipoca, sacrificada durante las celebraciones del mes Toxcatl (v. Olivier, 2003: 194-195). El representante del Espejo Humeante, como testifican algunas fuentes coloniales, vivía un año en gloria y riqueza para encontrar su muerte anunciada en el altar de sacrificio. El peregrino elige otro camino: se dirige al volcán, donde creará de sus lágrimas y de los montones de huesos una raza nueva, la mestiza, representada metonímicamente por veinte jóvenes de piel color de la canela, habladores de la lengua castellana (Fuentes, 2012: 547).

La tercera vez el peregrino se encuentra con su oscuro gemelo, esta vez en la forma doble de un barrendero desnudo y el Señor de la Gran Voz, tras una larga caminata, en la ciudad equivalente a la Gran Tenochtitlán. Tezcatlipoca no es el único personaje con el que se encuentra el peregrino: se vuelve a reunir también con su amante, la señora de las mariposas, ahora envejecida y "con los signos de la devastación en el rostro" (ob.cit: 564). Este personaje, una fusión de las diosas aztecas Izpapalotl y Tlazolteotl, podría ser interpretada como una alegoría del Nuevo Mundo, tanto con su encanto irresistible como con su "deslumbrante horror" (496). La relación íntima que el peregrino mantiene con ella a lo largo del relato puede también ser interpretada como la unión de los dos mundos. La señora de las mariposas es la madrehermana del peregrino-Quetzalcóatl con la que comete un incesto. El Señor de la Gran Voz es el testigo de la caída moral de su hermano-enemigo y le fuerza a enfrentar su condición, diciendo: "Mírate ahora, borracho, incestuoso, indigno, estúpido. No resististe a la tentación. El creador es culpable. El creador es tan débil como sus criaturas" (570). Aún más, el Señor de la Gran Voz revela al peregrino una imagen espantosa reflejada en los espejos de la vara que porta en su puño izquierdo: escenas "de muerte, degüello, incendio, espantable guerra" (571), protagonizadas por el peregrino, el hombre blanco: la imagen del lado oscuro de la conquista. Una vez más el peregrino se niega a asumir este destino: mata (o mejor dicho, piensa matar, tal y como creía haber matado al viejo de la memoria) a su oscuro doble con las tijeras traídas del viejo mundo. Su esfuerzo es vano, sin embargo. Tezcatlipoca aparecerá de nuevo, como siempre lo ha hecho. El anciano guardián de la memoria también reaparece y explica al peregrino los principios de la eterna lucha entre el bien y el mal: "Ese gemelo oscuro renacerá en ti, y seguirás combatiéndole. Y renacerá aquí. Volveremos a sufrir bajo su jugo. Volveremos a esperar que regreses a matarlo de nuevo" (578). 
El peregrino, como un personaje arquetípico simbólico del hombre blanco en América, tiene entonces una identidad dual. Es el portador de la cultura y el creador de una raza nueva; es el esperado Quetzalcóatl por un lado. Por el otro lado, es el conquistador despiadado, cegado por la avaricia, el que derrama la sangre y deja una huella de muerte; es el oscuro Tezcatlipoca. Los dos hermanos volverán a reunirse en la tercera parte de la novela en una lucha fratricida. En el futuro, el Espejo Humeante será el Presidente de la República Mexicana a servicio de los invasores norteamericanos y su hermano Quetzalcóatl será el defensor de "la libertad y la identidad de su pueblo" (Ordiz, 2003: 5-6). Tezcatlipoca y Quetzalcóatl siempre estarán enfrentándose en el eterno círculo de huida y regreso para reinar por un instante y ser derrotados de nuevo (Fuentes, 2012: 578). La historia se volverá a repetir en "épocas distintas, y mediante nuevas figuras" (ob.cit: 303), igual que en el cuadro de Orvieto.

La figura de Tezcatlipoca aparece también en la obra de Homero Aridjis, aunque con un valor simbólico diferente y en un contexto distinto. En La leyenda de los soles las características del dios azteca, e incluso su nombre, asume el personaje del temible general Carlos Tezcatlipoca, el jefe de la policía de la Zona Metropolitana de México en el año 2027. Tezcatlipoca mantiene el orden público con la ayuda de sus secuaces, los natocecas, responsables de las numerosas desapariciones de los ciudadanos "incómodos" en una ciudad desmesurada, degenerada, desfigurada, contaminada, sacudida por fuertes terremotos. Una ciudad donde desaparecen niñas adolescentes, raptadas y violadas por un criminal llamado El Tláloc. México en el año 2027 es una ciudad regida por la violencia, donde escasea no solo el agua sino también las moralidad básica, compasión y decencia. Es también una ciudad a borde de una catástrofe de dimensiones cósmicas: el fin del Quinto Sol. El título de la novela constituye una referencia explícita al mito cosmogónico preservado en varias fuentes escritas de la época colonial, por ejemplo Historia de los mexicanos por sus pinturas, Histoyre du Mechique, Memoriales de Motolinia, Anales de Cuauhtitlan, las obras históricas de Fernando de Alva Ixtilxochitl, y obviamente, Leyenda de los Soles del 1558 (Frankowska, 1987: 194). Aunque las versiones del mito de los soles o edades del mundo difieren en algunos detalles, como por ejemplo la secuencia de los soles, todas son portadoras del mismo mitema: el de la circular naturaleza del tiempo y de la historia. Los soles Ehécatl (del viento), Quiáhuitl (del fuego), Atl (del agua), Océlotl (de la tierra) y Ollin (del movimiento) se rigen por el mismo principio del nacimiento y destrucción (194-196). En la novela de Aridjis, al Quinto Sol preside José Huitzilopochtli Urbina, un gobernador corrupto, malvado y lujurioso. Su mano derecha es el Jefe de la Policía, quien viste siempre de negro y cubre su mirada dura como un pedernal con unas gafas para el sol. Sus subordinados le llaman El Jaguar. Tanto el presidente como el general hablan "el mismo lenguaje de la violencia indirecta" (Aridjis, 1993: 26). Como nota Carmen Vidaurre Arenas, en la novela distópica de Aridjis observamos no sólo "diversos procesos de mitificación [...], pero también de desmitificación" (2004b: 173). Lugares, personajes y acontecimientos "poseen características reales, vistas desde una perspectiva crítico-evaluadora y con frecuencia paródica, por el uso de la 
hipérbole" (2004b:173). Así el aparente don de la ubicuidad del general queda explicado por varios trucos de sus empleados, "cambios de agenda, traslados sorpresivos" (ibid.: 173). El carácter malévolo de Tezcatlipoca se explica por las circunstancias familiares (es hijo de un narcotraficante y una madre de cuestionable moralidad), por su pasado como sicario y por su formación en el Colegio Militar (Aridjis, 1993: 25-26). El desastroso estado de la ciudad puede ser explicado por la degenerativa actitud de sus gobernantes, que resulta en una contaminación catastrófica en el nivel ecológico y en la corrupción, violencia y terror en el nivel político-social. De este modo, la novela puede estar interpretada como una crítica de algunos fenómenos de la sociedad mexicana actual. Para el propósito del nuestro trabajo, sin embargo, nos detendremos en el análisis mitopoético de la novela.

Mientras la reinterpretación de la figura del dios Tezcatlipoca es fácil de identificar en la novela, la identidad de su rival mítico Quetzalcóatl no resulta tan explícita. No obstante, el personaje de Cristóbal Cuauhtli, un joven indígena que aparece en la puerta de la casa de Juan de Góngora, el protagonista de la novela, posee algunos rasgos de la Serpiente Emplumada. Cuauhtli en náhuatl significa "águila", la ave que en la mitología azteca es la adversaria del jaguar. Como explica Pablo Escalante Gonzalbo,

las aves, y especialmente el águila, eran vistas como representantes de una de las mitades del cosmos; eran del fuego, del día; los jaguares, por su parte, eran de agua y de la noche. Durante los últimos 800 años de su historia, los pueblos mesoamericanos parecen haber preferido la lucha entre el águila y el jaguar como metáfora de la confrontación cósmica. (2002: 51)

Cristóbal Cuauhtli es el guardián del apócrifo Códice de los soles, un libro rescatado de la hoguera, que contiene los glifos calendáricos de "la fecha del nacimiento del Quinto Sol, y su fecha de muerte" (Aridjis, 1993: 38). El libro revela también un gran secreto: "Si mańana muere Tezcatlipoca, la diosa azul, que vive en el Iztac Cíhuatl, será la diosa del Sexto Sol, el Sol de la Naturaleza. Si muere ella, el general Carlos Tezcatlipoca tomará el poder para instaurar el reino del terror nocturno, el Sol del Espejo Humeante" (40). Cristóbal Cuauhtli y Juan de Góngora entonces emprenden el rescate de una de las páginas del códice, robada por el general, la hoja "que revela el día del fin del Quinto Sol y el nombre del dios que va a formar el Sol futuro" (102). Para lograr ese propósito, Juan de Góngora tiene que entrar en la casa del jefe de la policía en la siniestra Colina Negra.

Cuauhtli y Góngora llegan a la sede del general a las nueve menos tres, una hora compuesta por los números sagrados de los aztecas (tres niveles del mundo, nueve niveles del inframundo). En la casa de Tezcatlipoca no faltan espejos: Cuauhtli advierte a su amigo pintor que no se mire en ellos, para no ver su condición fantasmal. En un patio de esculturas, estatuas de Xipe Tótec, Huitzilopochtli y Tezcatlipoca forman "una trinidad perversa, la trinidad del sacrificio humano" (107). Más lejos hay "estatuas del presidente de la República y de los héroes del Partido Único de la Revolución. En las fauces abiertas de un dios, Quetzalcóatl, estaba encajado el rostro del general 
Tezcatlipoca, con sus lentes negros" (107). En ese templo espantoso no puede faltar un altar: tiene la forma de una mesa redonda sobre la que yace el esqueleto del señor de la muerte guardando un quauhxicalli, el recipiente para los corazones de los hombres sacrificados en honor del Sol (108). Perseguido por los nacotecas y espantando por un gato enorme, multiplicado en los espejos negros, Góngora huye de la Colina Negra sin recuperar a la página robada. Su miedo le impide evitar la victoria del Espejo Humeante.

Cuauhtli muere, eliminado (indirectamente, por supuesto), por el general malvado. En un golpe de estado, Tezcatlipoca mata al presidente Huitzilopochtli, se apodera del gobierno y se declara presidente de la República. Las campanas de la Catedral proclaman el fin del Quinto Sol. Los ciudadanos congregados en el Zócalo experimentan una especie de la repetición de la Noche Triste, entre "detonaciones, exclamaciones y disparos de arma de fuego" (161). Al mundo salen los grotescos tzitzimime, monstruos del crepúsculo, liderados por Mixcóatl. Parece que el destino del mundo está señalado: Tezcatlipoca triunfa.

Sin embargo, en un giro inesperado de la trama, a Tezcatlipoca lo matan por accidente los hermanos Saturno, investigadores del caso del Tláloc. Son ellos quienes descubren la verdadera identidad del general: es él, de hecho, El Violador del Alba, quien secuestraba a las adolescentes para violar y matarlas. Como lee Juan de Góngora en un manuscrito (supuestamente la Leyenda de los soles, traducida del mexicano al castellano por fray Bernardino de Sahagún): "El Sol también muere. Hay un lugar en el espacio para los soles muertos. El Sol también nace, hay un lugar en el espacio para los soles que se están gestando. Mientras nuestro Sol se acaba, hay otros soles en el vientre de la noche, envueltos en la placenta cósmica del polvo y el gas moleculares" (195). Observamos entonces, que la reinterpretación de Aridjis del mito nahua conserva el mismo mitema: el de la circular naturaleza del tiempo y del renacimiento de la nueva era tras la destrucción de la edad antecedente. Para la cuidad de México de Aridjis hay esperanza: la novela termina con la descripción de la "figura azul de una mujer que tenía los brazos extendidos hacia el Sol, como sie quisiera tomar de él el calor y el esplendor de la mañana" (198). Es la diosa de la naturaleza, la señora del Sexto Sol.

La Leyenda de los soles no es la única novela de Aridjis donde se reinventa la figura de Tezcatlipoca en el contexto de la crítica social. También el Señor de la Frontera en Los perros del fin del mundo posee rasgos de esta deidad: "El Señor es como Tezcatlipoca: está en todas partes y en ninguna" (Aridjis, 2012: 76). Nadie sabe exactamente quién es, tiene muchos nombres y apodos, curiosamente femeninos. Dirige el cártel más poderoso de Ciudad Juárez, donde reina la violencia, impunidad, prostitución, narcotráfico, corrupción y la falta total del respeto a los derechos humanos más básicos. $\mathrm{El}$ Señor tiene también un cinturón de seguridad gracias al que parece poseer en don de la ubicuidad: "los oídos y los ojos de los halcones que recorren la periferia en coche moto o a pie y avisan de los movimientos del ejército y la policía, y de los cárteles rivales que entran a la ciudad" (77). Ciertas referencias a Tezcatlipoca encontramos también en el personaje del señor Q, uno de los duros de la Ciudadcita en Señales que precederán al fin del mundo de Yuri 
Herrera. El señor Q también es un narcotraficante poderoso, con la sede en el Casino, al que conduce un pasillo de espejos. El señor Q viste habitualmente de negro, nunca alza la voz, pero las palabras que brotan de su boca son tan duras como piedras (Herrera, 2010: 23). Él tiene en sus manos el destino de Makina, la protagonista de la novela, ya que de él depende si Makina vuelve del Gran Chilango al que se dirige en búsqueda de su hermano. Las dos novelas, de Aridjis y de Herrera, muestran ciertos pararelismos adicionales. Los protagonistas, José Navajas y Makina respectivamente, viajan al inframundo acompańados por un perro real o metafórico: José por su perro xolo llamado Pek y Makina por Chucho (palabra mexicana que denota un perro), un pollero a servicios del señor Q (o el señor $\mathrm{H}$, si éste le encarga una chamba), quien se ocupa de pasar a los migrantes a los Estados Unidos. Ambos protagonistas también viajan por los nueve niveles del inframundo mexica; en la novela de Herrera incluso los títulos de los capítulos corresponden (con algunas modificaciones) a los nombres de estos nueve niveles míticos. José Navaja en su recorrido por el Inframundo, que parece reflejar el Supramundo de México, se encuentra con una de las víctimas del Seńor de la Frontera, con Moctezuma Xocoyotzin y con varios dioses aztecas, entre ellos con Tezcatlipoca, el dios

con fama de embaucador y de intrigante, que provocaba guerras y discordias, espantaba de noche y chupaba a los niños, tenía la capacidad de leer los pensamientos y descubrir los secretos del corazón, hacerse transparente y transformarse en muchos y en ninguno. "El Oscuro", "El Nocturno", que antańo había presidido sobre el "sol de la tierra" triunfando sobre Quetzalcóatl, el "sol del viento"; tenía cerca de ochenta nombres, entre los que figuraban Youhalli Ehécatl, "viento de la noche", Nacac Yaotl, enemigo de ambos bandos, Tepeyollotl, "corazón de la montaña", "jaguar nocturno". (Aridjis, 2012: 190)

Observamos entonces que tanto Aridjis como Herrera reelaboran los mitos y las creencias indígenas para ilustrar algunos aspectos de la realidad socio-política mexicana actual, sobre todo los relacionados con la violencia, el narcotráfico y la emigración.

Para terminar el breve recorrido por las reinterpretaciones de la figura de Tezcatlipoca en la narrativa mexicana mencionaremos también el valor simbólico que tiene Tezcatlipoca en el relato de Bernardo Esquinca Los niños de paja. En la trayectoria literaria del escritor jaliscience destaca su fascinación por el pasado indígena de México, por la novela de terror, y por la cinematografía. Estos tres elementos se juntan en Los niños de paja. En un ambiente de pesadilla, la historia de cuatro amigos obligados por falta de gasolina a pasar la noche en un pueblo misterioso, transcurre durante una noche, la víspera de Todos los Santos. Muy pronto los desafortunados viajeros notan que en el pueblo faltan nińos y que la ubicua e inquietante luz azul de la televisión encendida en un canal muerto se parece a "un ojo sin párpado que todo lo observa" (Esquinca, 2008: 74). Los niños se encuentran en un pueblo vecino y están preparándose para una guerra contra los adultos. Su aspecto infantil contrasta con su violencia, sus miradas parecen esconder un misterio "sin tiempo y sin edad" (80). De hecho, no parece posible que sean niños, ya que vinieron al pueblo hace medio siglo de los Estados Unidos con sus padres. 
Resulta que el pueblo de los niños fue construido como "una pequeña réplica en madera de un típico pueblo estadounidense del otro lado del bosque, para que los niños tuvieran un sitio dónde jugar" (79). El parque infantil, en vez de un lugar seguro y lleno de risas, se convirtió en un lugar de castigo, donde los padres dejaban a sus niños para que pasasen noches llenas de miedo en la oscuridad. Una de las noches de castigo resulta en tragedia: durante la tormenta muere una de las nińas. Los niños optan por quedarse en las casas de campo en un acto de desafío a los padres, a quienes estorbaban. Su actitud violenta expresa "un resentimiento hacia el mundo adulto, una necesidad de revancha y de liberación ante la tiranía autorizada" (98). Parece apropiado que su ángel protector sea Tezcatlipoca, el dios de la oscuridad, el conocedor de los secretos de la mente humana, el sembrador de discordias, quien ahora se manifiesta en la electricidad y con el que los niños hicieron un pacto para no crecer, no convertirse en sus padres (99). La crueldad de los adultos "había despertado un inframundo que yacía, latente, bajo aquellos pueblos" (113). Tezcatlipoca se apoderó de las mentes infantiles y los niños, a los que sus padres no dejaron crecer, se convirtieron en los niños de paja, "secos por dentro" (99). Maltratados, vejados, abandonados, llenos de miedos infantiles que nadie supo aliviar, los nińos encuentran su patrón en el Espejo Humeante y se vuelven en contra de los adultos.

A lo largo de este trabajo hemos analizado algunos ejemplos de la reelabroación de la figura de Tezcatlipoca y los mitos relacionados con él en la narrativa mexicana del siglo XX y XXI. Ángel Rama (2012) ya apuntó a la inclusión del mito y del pensamiento mítico en la literatura como una de las facetas de la transculturación narrativa. Tezcatlipoca, igual que otras manifestaciones culturales y religiosas indígenas, se negó a morir, aniquilado por la conquista y siglos de colonialismo. Regresó, renació, recuperado por la literatura mexicana moderna, con toda su riqueza simbólica. No obstante, las reinterpretaciones de la figura del Espejo Humeante se inscriben dentro de una cultura nueva, transformada, en un contexto diferente del original. Tezcatlipoca se adaptó a la nueva realidad mexicana, mostrando varias caras. En Terra Nostra de Carlos Fuentes llega a simbolizar el lado oscuro de la conquista y de la historia en general, vistas desde la perspectiva de quien indaga sobre la identidad nacional mexicana. La rivalidad entre Tezcatlipoca y Quetzalcóatl ilustra la circular naturaleza del tiempo y la dualidad de la realidad histórica, de la vida y de la muerte unidas por la memoria (Fuentes, 2012: 484). El motivo de este antagonismo aparece también en La leyenda de los soles de Homero Aridjis en un contexto socio-político del México actual, con un trasfondo ecologista. La imagen de Tezcatlipoca se reinventa en relación con el mundo del poder, la violencia y el narcotráfico en Los perros del fin del mundo de Aridjis y Señales que precederán al fin del mundo de Herrera. Por fin, el oscuro dios de la guerra reaparece en la narrativa de terror en Los niños de paja de Bernardo Esquinca.

La inclusión del mito indígena en la narrativa moderna asegura sobre todo la perduración de la herencia cultural prehispánica. Sin embargo, en vez de recontar los mitos antiguos, la literaura mexicana los reformula y reinterpreta, subrayando su valor universal y su vigencia para la actualidad 
mexicana transulturada, incomprehensible e impenetrable sin la incorporación del pensamiento mítico arraigado en la mentalidad colectiva de una nación mestiza e heterogénea. Tezcatlipoca seguramente volverá a la literatura: no está en su naturaleza desaparecer para siempre. Nos queda sólo observar de qué manera y en qué contexto estará reinterpretado en las décadas futuras.

\section{BIBLIOGRAFÍA}

ARIDJis, Homero (1993), La leyenda de los soles. México, Fondo de Cultura Económica.

ARIDJIS, Homero (2012), Los perros del fin del mundo. México, Santillana Ediciones Generales.

Díaz del Castillo, Bernal (1998), Historia verdadera de la conquista de Nueva España. Barcelona, Plaza \& Janés Editores.

Escalante Gonzalbo, Pablo (2002), "Primer espejo", en: Florescano, Enrique (ed.), Espejo mexicano. México, Consejo Nacional para la Cultura y las Artes.

EsQUiNCA, Bernardo (2008), Los niños de paja. Oaxaca de Juárez, Oaxaca, Edditorial Almadía.

FranKOWSKA, Maria (1987), Mitologia Azteków. Warszawa, Wydawnictwa Artystyczne i Filmowe.

FUENTES, Carlos (1982), Los días enmascarados. México, Ediciones Era. (2000), Los cinco soles de México. Barcelona, Seix Barral. (2012), Terra Nostra. México, Santillana Ediciones Generales.

Herrera, Yuri (2010), Señales que precederán al fin del mundo. Cáceres, Editorial Periférica.

Heyden, Doris (1989), "Tezcatlipoca en el mundo náhuatl", en Estudios de Cultura Náhuatl, Universidad Nacional Autónoma de México, vol. 19, pp. 84-93.

JASTRZĘBSKA, Adriana Sara (2013), Jak przyszłość ukształtowała przeszłość. Metapowieść historiograficzna w Ameryce Łacińskiej. Bielsko-Biała, Wydawnictwo Naukowe Akademii Techniczno-Humanistycznej w BielskuBiałej.

Miller, Mary; Taube, Karl (1993), An Illustrated Dictionary of The Gods and Symbols of Ancient Mexico and the Maya. London, Thames \& Hudson Ltd.

Morales, Mario Roberto (1996), «Aldea oral/ciudad letrada: la apropiación vanguardista de lo popular en América Latina», en Revista Iberoamericana, University of Pittsburgh, Vol. LXII, Núm. 175, pp. 405-420. 
Olivier, Guilhem (2003), Mockeries and metamorphoses of an Aztec God. Tezcatlipoca, "Lord of the Smoking Mirror". Boulder, University Press of Colorado.

ORDIZ, Francisco Javier (2003), "Mito e identidad en la obra de Carlos Fuentes". Ponencia presentada en las Jornadas de Literatura, Crítica y Medios: perspectivas 2003, Facultad de Filosofía y Letras, Universidad Católica Argentina, Buenos Aires.

http://bibliotecadigital.uca.edu.ar/repositorio/ponencias/mito-e-identidadfuentes.pdf (consultado en junio 2016).

RamA, Ángel (2012), Writing across Cultures. Narrative transculturation in Latin America. Durham and London, Duke University Press.

Rowe, William; Schelling, Vivian (1991), Memory and Modernity. Popular Culture in Latin America. London, New York, Verso.

Sahagún, Bernardino de (2010), Historia general de las cosas de Nueva España, Volumen 1. New York, Cambridge University Press.

Vidaurre ARenas, Carmen (2004a), Los signos del laberinto: Terra Nostra de Carlos Fuentes. Guadalajara, Universidad de Guadalajara.

(2004b), Galería de ecos. Análisis sobre narrativa mexicana. Guadalajara, Universidad de Guadalajara.

Williams, Raymond Leslie (1996), The writings of Carlos Fuentes. Austin, University of Texas Press. 